\title{
Delav between Breast Cancer Detection and Arrival at Specialist Clinic Preliminary Revelations of Multicentered Survey in Nigeria
}

Artilce by Agodirin $\mathrm{O}^{1,12}$, Olatoke $\mathrm{S}^{1}$, Rahman $\mathrm{G}^{1,2}$, Kolawole $\mathrm{O}^{3}$, Oguntola $\mathrm{S}^{4}$, Olasehinde $\mathrm{O}^{5}$, Ayandipo $\mathrm{O}^{6}$, Olaogun $\mathrm{J}^{7}$, Katung $\mathrm{A}^{8}$, Etonyeaku $\mathrm{C}^{9}$, Habeeb $\mathrm{O}^{1}$, Adeyeye $\mathrm{A}^{1}$, Agboola $\mathrm{J}^{10}$,

Akande $\mathrm{H}^{1}$, Akanbi $\mathrm{O}^{4}$, Abiyere $\mathrm{H}^{11}$, Fatudimu O. ${ }^{11}$

${ }^{1}$ University of Ilorin Teaching Hospital, Ilorin Nigeria

${ }^{2}$ Cape Coast Teaching Hospital, Cape Coast Ghana

${ }^{3}$ LAUTECH Teaching Hospital, Osogbo Nigeria

${ }^{4}$ LAUTECH Teaching Hospital, Ogbomoso Nigeria

${ }^{5}$ Obafemi Awolowo Teaching Hospital, Ile-Ife Nigeria

${ }^{6}$ University College Hospital, Ibadan Nigeria

${ }^{7}$ Ekiti State Teaching Hospital, Ado-Ekiti Nigeria

${ }^{8}$ Federal Medical Center, Owo Nigeria

${ }^{9}$ Obafemi Awolowo Teaching Hospital, Ilesha Nigeria

${ }^{10}$ General Hospital, Ilorin Nigeria

${ }^{11}$ Federal Teaching Hospital, Ido-Ekiti Nigeria

${ }^{12}$ Texila America University, Guyana South America

E-mail: cancer1992@yahoo.com ${ }^{1}$

\begin{abstract}
Delay between breast cancer detection and arrival at specialist clinic. Preliminary revelations of multicenter survey in Nigeria

Background: Level of breast cancer awareness and rate of late presentation usually have inverse relationship. The parallel relationship witnessed in Nigeria is a paradox requiring urgent intervention.

Aim: To understand the paradox, we described the patient's journey from lump detection to arrival at the specialist clinic. Barring awareness, identifying where the major delays still resided will help to redirect our strategies in the control of breast cancer scourge.

Method: Cross-sectional multicenter questionnaire based survey conducted in surgery outpatient clinics of 10 tertiary institutions in North central and Southwestern Nigeria. Face-to-face interview was conducted using pretested questionnaire. Data was analyzed using SPSS, version 18. p-value was set at 0.05.

Results: One hundred newly diagnosed women responded in this preliminary analysis. Age ranged 2680 years (mean 50.5 \pm 13.2$)$. Eighty-one $(81 \%)$ were aware of breast cancer before detecting their lump $(s)$. Eighty-eight (88\%) had lumps $\leq 5 \mathrm{~cm}$ at detection. Sixty-nine (69\%) $(p=0.0001)$ visited the first orthodox personnel when their lumps were $\leq 5 \mathrm{~cm}$. Only 39(39\%) arrived at specialist clinic when their lumps were $\leq 5 \mathrm{~cm}$. Ninety-five respondents $(95 \%)(p=0.0001)$ visited orthodox personnel first to seek treatment. The first personnel was general practitioner $72 \%$ of the times $(p=0.0001)$ (see figure 2). Fifty-eight $(58 \%)$ consulted the first orthodox personnel within 8 weeks ( $p=0.133)$. Only 26\% arrived at a specialist clinic within 8 weeks $(p=0.0001)$. Mean interval from detection to first personnel was shorter (61 days) than mean interval between first personnel and specialist clinic (157 days) $(P=0.0001)$

Conclusion: The longest stretch of journey was between the first orthodox consultation and the specialist clinic.
\end{abstract}

Keywords: breast cancer, detection, Journey to specialist clinic.

\section{Background}

Breast cancer patients continue to arrive late to specialist clinic in Nigeria despite increasing awareness. The relationship between level of awareness and rate of late presentation should be inverse, the parallel relationship witnessed in Nigeria is paradoxical and it suggests a deficiency which requires urgent intervention. 
DOI: $10.21522 / \mathrm{TIJPH} .2013 .05 .04$. Art053

ISSN: $2520-3134$

Poor outcome of breast cancer management in Nigeria and low-income countries in general is linked to delays along the continuum of detection to treatment. In Nigeria, the bedrock of the fight against breast cancer has been to increase awareness. Therefore, enormous effort and millions of naira is expended on campaigns, awareness boosting programs and provision of screening facilities by the Government, indigenous and international Non-Governmental Organizations. Despite reports of increasing levels of awareness(1-8) our specialist clinics continue to receive breast cancer patients at late stages when treatment is least effective and least rewarding $(9,10)$.

In our quest to understand the existing paradox, we undertook this research among breast cancer patients to describe the journey from lump detection to arrival at the specialist clinic. Barring awareness, we hoped to identify where the major delays still resided. This information will help to re-direct our strategies in the control of breast cancer scourge.

Based on a pilot study where we found that $80 \%$ of patients presented to the first orthodox medical personnel within 30 days of detecting their breast lumps, we postulated that majority of the delay was after first contact with orthodox personnel. This is a report of our preliminary analysis.

\section{Method}

This was a cross-sectional study on breast cancer patients in Surgical Outpatient clinics of 10 tertiary health institutions in North central and Southwestern Nigeria. It was a semi-structured questionnaire-based design. After ethical approval, face-to-face interview was conducted using a specially designed and pretested questionnaire. We requested information on patients' socio-demography, chronology of events relating to detection, disclosure and contact with orthodox personnel for care. All newly diagnosed patients above 18 years were included. Language barrier, mental incapacitation and recurrent lumps were reasons for exclusion.

\section{Hypothesis and sample size determination}

From our pilot study $80 \%$ of patients had tumors estimated to be less than $5 \mathrm{~cm}$ at first orthodox contact and $80 \%$ made the first orthodox contact within 30 days of detection of lesions. We hypothesized that among breast cancer patients who presented to outpatient specialist surgical/breast clinic for the first time, 1) majority visited orthodox personnel before traditional, 2) majority presented to the first orthodox personnel within 8 weeks of noticing their breast lumps and 3) majority presented to the first orthodox personnel when their lumps were estimated to be $\leq 5 \mathrm{~cm}$ diameter. Using the sample size calculation for descriptive cross-sectional study at a relative precision of 5\% and confidence level of $95 \%$ (1.96), the minimum sample size required to test our hypothesis was 384 respondents. Considering a nonresponse rate of $10 \%$, we required a maximum of 423 respondents. Data was analyzed using SPSS, version 18. p-value was set at 0.05 .

In this preliminary report, we analyzed response from the first 100 patients. At the time of this report, there was no well-structured system of care and referral for breast cancer patient in Nigeria. Consequently, majority of patients expected to receive adequate care from whichever health personnel they have always entrusted with their health. The data in this report was interpreted based on this premise.

\section{Results}

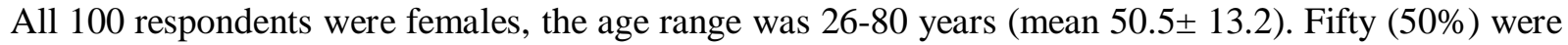
postmenopausal. Eighty-one ( $81 \%$ ) were aware of breast cancer before detecting their lumps.

\section{Estimated size at lump detection}

Among the 100 respondents, 88 (88\%) estimated their lumps to be $\leq 5 \mathrm{~cm}$ at detection. Sixty-nine (69\%) $(\mathrm{p}=0.0001)$ visited the first orthodox personnel when their lumps were estimated to be $\leq 5 \mathrm{~cm}$ and $39(39 \%)$ visited the first specialist clinic when their lumps were estimated to be $\leq 5 \mathrm{~cm}$.

\section{Journey of disclosure}

Fifty-seven (57\%) informed someone about their lumps within 1week, 65(65\%) informed someone within 2 weeks and $81 \%$ informed someone within 4 weeks. The first person informed was the husband $50 \%$ of the times (see figure 1). The first person advised visiting a doctor, nurse or hospital $75 \%$ of the 
times (see table 1). Seventy-three (73\%) of respondents acted on the advice given by the first person within 2 weeks.

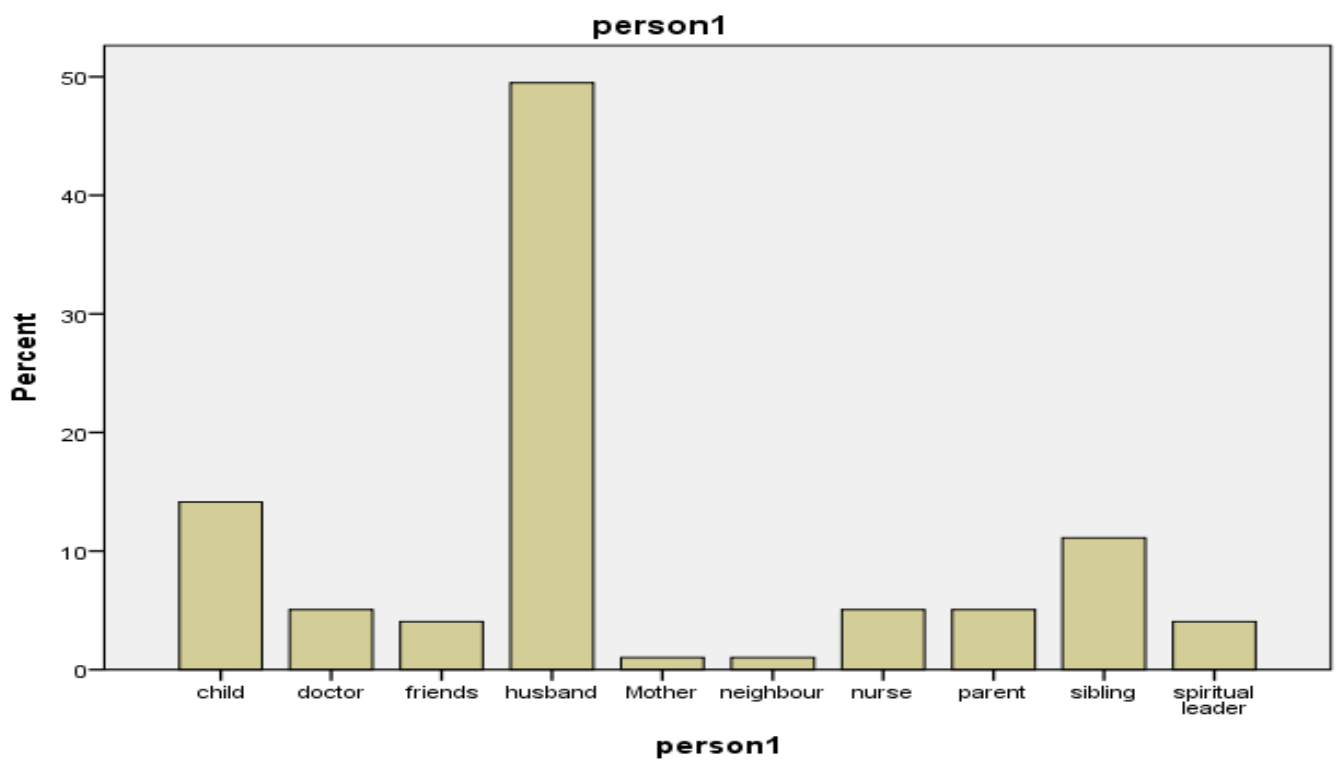

Figure1. First person informed

Advice offered by first person informed table1

\begin{tabular}{|ll|}
\hline Advice offered & Frequency (\%) \\
\hline Go Hospital/consult Doctor/Consult Nurse & $75(75)$ \\
Observe/ reassured & $13(13)$ \\
Consult spiritual leader/ Pray and fast & $9(9)$ \\
Use antibiotics/apply hot forment & $3(3)$ \\
\hline
\end{tabular}

\section{Journey to specialist}

Ninety-five respondents $(95 \%)(\mathrm{p}=0.0001)$ visited orthodox personnel first to seek treatment, 5 percent visited traditionalist or a religious leader first. The firsts orthodox personnel was general practitioner or family physician $72 \%$ of the times $(\mathrm{p}=0.0001$ ) (see figure 2 ). Forty percent consulted the first orthodox personnel within 2 weeks, 54 percent within 4 weeks and $58 \%$ within 8 weeks $(\mathrm{p}=0.133)$. Seven percent arrived at a specialist clinic within 2 weeks, $14 \%$ arrived at a specialist clinic within 4 weeks and $26 \%$ arrived at a specialist clinic within 8 weeks $(\mathrm{p}=0.0001)$. The mean interval from detection to first orthodox personnel was 61 days, while the mean interval between first orthodox personnel and first specialist clinic was 157 days (see table 2$)(\mathrm{P}=0.0001)$ 
DOI: $10.21522 / \mathrm{TIJPH} .2013 .05 .04 . \mathrm{Art} 053$

ISSN: $2520-3134$

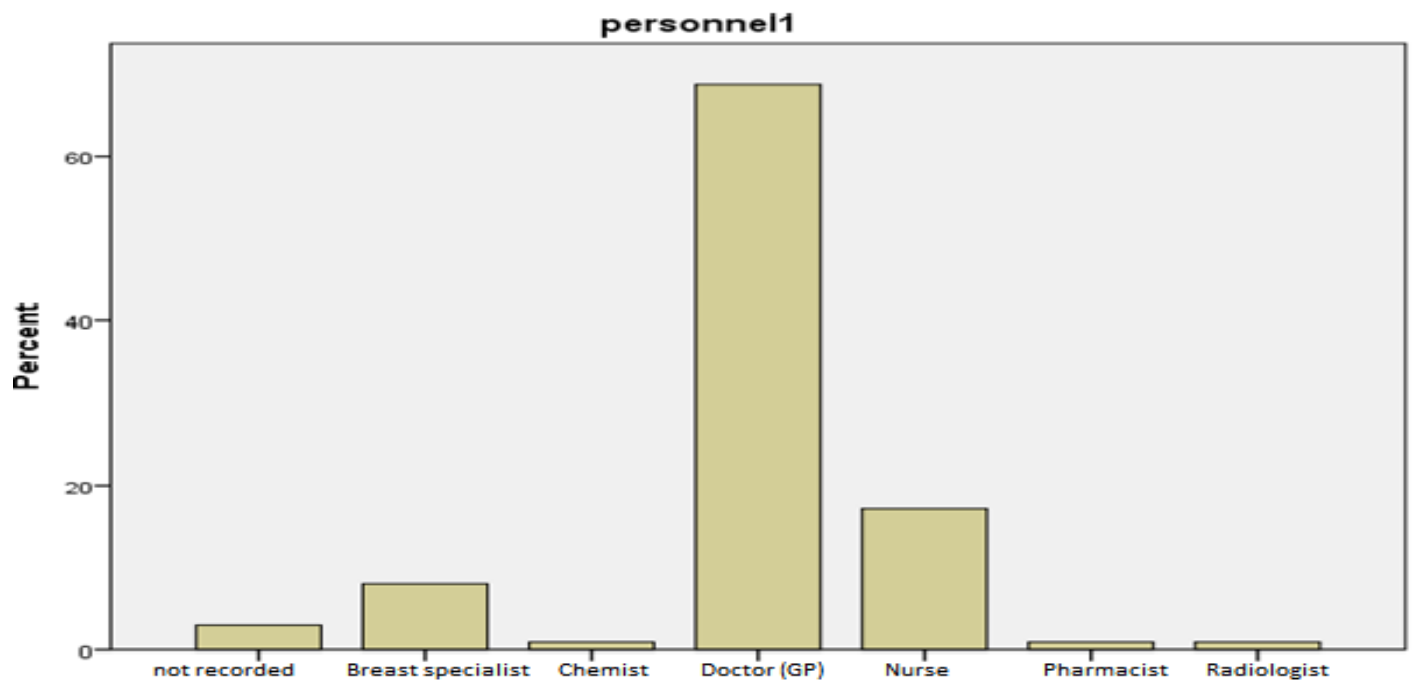

Figure 2. First orthodox personnel consulted

Table 2. Comparison of intervals

\begin{tabular}{|l|l|l|}
\hline Interval in days & Mean & P value $=0.0001$ \\
\hline Interval between detection and getting to first orthodox & $60.3 \pm 67$ & \\
\hline Interval between first orthodox and getting to specialist clinic & $157 \pm 202$ & \\
\hline \multicolumn{2}{|c|}{ (Confidence Interval: 49.2 days, 144days) } \\
\hline
\end{tabular}

\section{Discussion}

Breast cancer patients continue to arrive late at specialist clinics in Nigeria and many low and middleincome countries. A report among Libyan women found median delay of 4 months between lump detection and arrival at orthodox medical consultation. Another study in Malaysia found that only about a third of women sought orthodox consultation within one month of finding their lump(s) (11, 12). Late arrival escalates the overall burden of treatment; it necessitates unwanted mutilating surgeries and thus worsens the physical, and psychological implications. It multiplies the monetary cost of treatment and at the same time lowers chances of survival.

Poor awareness has been the focus for control of breast cancer in Nigeria for more than 2 decades now. However, recent reports are suggesting the probable need to review our strategy in favor of other competing factors such as patient adherence and navigation $(8,13-15)$. In response to this suspected change in trend, our study was directed at describing the journey of a breast cancer patient from lump detection to arrival at a specialist clinic.

Data from a hundred respondents constituting a quarter of the planned overall sample size were analyzed in this report. Majority of the respondents were aware of breast cancer before noticing their lump(s), this conformed with recent reports and a systematic review showing that majority of respondents in Nigeria were aware of breast cancer(8). The weighted average level of awareness according to the systematic review was $80.7 \%$.

\section{Estimated size at lump detection}

Close to $90 \%$ of respondents in this study had lumps estimated to be $\leq 5 \mathrm{~cm}$ at detection, this fraction reduced by $22 \%$ before visiting the first orthodox personnel and by $55 \%$ before arrival at first specialist clinic. This meant that while majority found their lumps at sizes less than $5 \mathrm{~cm}$, most lump had grown to sizes above $5 \mathrm{~cm}$ diameter at first consultation in the specialist clinic. The reduction in fraction was larger between first orthodox consultation and specialist clinic than between detection and first orthodox 
consultation. The specialist clinic is where the diagnosis is made, record of orthodox visit is kept and research reports commonly emanate. The study among Libyan women showed a reverse trend where time to diagnosis was shorter after first orthodox consultation than the time between detection and first orthodox consultation (12). The Libyan study however did not state whether the orthodox consultation was specialist clinic.

\section{Journey of disclosure}

Most patients informed someone about their lump(s) within 4 weeks, majority did so within 1 week of noticing their lump(s). Comfortingly, two-thirds of the informed persons offered adequate advice and majority of patients acted on the advice given by the person informed. The husband was the first to be informed in most cases.

The husband's angle is a newly revealed significant gap in our strategy against breast cancer. This gap has not been adequately employed. It is rare to find research on breast cancer targeting husbands/men from Nigeria. Only one of such studies was found, it was the report of a research by Adeoti et al seeking the opinion of men about assisting to detect lumps in their spouse's breast(16). Among 51 studies reviewed by Agodirin et al in their systematic review dwelling on the levels of awareness of breast cancer in Nigeria, only 2 included males and among close to 20,000 respondents only 316 were males(8).

\section{Journey to specialist}

In this study, $95 \%$ of respondents $(95 \%)(\mathrm{p}=0.0001)$ visited orthodox personnel first to seek treatment and the first orthodox personnel was a general practitioner on most occasions. Even though the numerical value (57\%) was in favor of majority visiting the personnel within 8 weeks, it was not statistically significant $(\mathrm{p}=0.133)$. There was however a marked reduction in the fraction arriving in the specialist clinic within 2 , 4 and 8 weeks ( $\mathrm{p}=0.0001$ ). Also, the mean interval from detection to first orthodox personnel (61 days) was significantly different from the mean interval between first orthodox personnel and first specialist clinic (157 days) (see table).

\section{Conclusion}

While we await the final report, this preliminary review showed that majority of breast cancer patients found their lumps when they were relatively early. Majority of breast cancer patient presented to orthodox medical personnel first. The narrowest bottleneck in the journey of the breast cancer from detection to specialist was between the first orthodox consultation and the specialist clinic.

While we continue to raise awareness, to draw attention to the bottleneck between first orthodox consultation and specialist clinic where research reports commonly emanate, we recommend that the term "late presentation" which targets the interval between lump detection and orthodox consultation be extend and rephrased as "late presentation to specialist clinic" or "late representation to orthodox care.

Based on this preliminary review our strategy should be at least two-pronged; we target the interval between detection and first orthodox caregiver and we the interval between the first orthodox caregiver and the specialist.

Funding: This research was supported by grant from African Research Group for Oncology (ARGO)

\section{References}

[1]. Akanbi oO, A. Adeoti, M. Aderounmu, A. Idris, O. Abayomi, O. Delay presentation of breast cancer: A study among south western Nigerian women. International Journal of Current Research. 2015;7.

[2]. Adeoti M, Agodirin O, Odu O, Oguntola A, Bello T, Aderounmu A. The role of men in early detection of their spouses' breast lump(s)/cancer. The Nigerian Journal of General Practice. 2011; 9(2).

[3]. Azubuike S, Okwuokei S. Knowledge, attitude and practices of women towards breast cancer in Benin City, Nigeria. Ann Med Health Sci Res. 2013; 3(2):155-60.

[4]. Amosu A, Degun A, Thomas a, Babalola O. Assessment of awareness, perception, specific knowledge, and screening behavior regarding breast cancer among rural women in Ipokia local government area. Ogun State Nigeria. Archives of Applied Science Research. 2011; 3(2):253-65. 
DOI: $10.21522 / \mathrm{TIJPH} .2013 .05 .04$. Art053

ISSN: $2520-3134$

[5]. Babatunde AS, B. Agboola, J. Nwokoro, C. Belief and practices associated with late presentation in patients with breast cancer; an observational study of patients presenting in a tertiary care facility in Southwest Nigeria. African Journal of Cancer. 2015; 7(4):178-85.

[6]. Ermiah E, Abdalla F, Buhmeida A, Larbesh E, Pyrhonen S, Collan Y. Diagnosis delay in Libyan female breast cancer. BMC Research Notes. 2012; 5:452.

[7]. Ezeome ER. Delays in presentation and treatment of breast cancer in Enugu, Nigeria. Niger J Clin Pract. 2010; 13(3):311-6.

[8]. Isara AR, Ojedokun CI. Knowledge of breast cancer and practice of breast self-examination among female senior secondary school students in Abuja, Nigeria. J Prev Med Hyg. 2011; 52(4):186-90.

[9]. Norsa'adah B, Rampal KG, Rahmah MA, Naing NN, Biswal BM. Diagnosis delay of breast cancer and its associated factors in Malaysian women. BMC Cancer. 2011; 11:141.

[10]. Oche M, Ayodele S, Umar A. Breast cancer and mammography: current knowledge attitudes and practices of female health workers in tertiary health institution in Northern Nigeria. Public Health Research. 2012; 2(5):114-9.

[11]. Olayide AS, Halimat AJ, Samuel OA, Ganiyu RA, Soliu OA. Level of Awareness and Knowledge of Breast Cancer in Nigeria. A Systematic Review. Ethiop J Health Sci. 2017; 27(2):163-74.

[12]. Oluwatosin OA, Oladepo O. Knowledge of breast cancer and its early detection measures among rural women in Akinyele Local Government Area, Ibadan, Nigeria. BMC Cancer. 2006; 6:271.

[13]. Olugbenga-Bello A, Oladele EA, Bello TO, Ojo JO, Oguntola AS. Awareness and breast cancer risk factors: perception and screening practices among females in a tertiary institution in Southwest Nigeria. Niger Postgrad Med J. 2011; 18(1):8-15.

[14]. Oladimeji KE, Tsoka-Gwegweni JM, Igbodekwe FC, Twomey M, Akolo C, Balarabe HS, et al. Knowledge and Beliefs of Breast Self-Examination and Breast Cancer among Market Women in Ibadan, South West, Nigeria. PLoS One. 2015; 10(11):e0140904.

[15]. Sharma K, Costas A, Shulman LN, Meara JG. A systematic review of barriers to breast cancer care in developing countries resulting in delayed patient presentation. J Oncol. 2012; 2012:121873.

[16]. Tobin E, Okeowo P. Breast self-examination among secondary school teachers in south-south Nigeria: A survey of perception and practice. Journal of Public Health and Epidemiology. 2014; 6(5):169-73. 